\title{
BMJ Open Primary medication non-adherence at Counties Manukau Health Emergency Department (CMH-ED), New Zealand: an observational study
}

Nataly Dominica Martini (D) , ${ }^{1}$ Bert van der Werf (D) , ${ }^{2}$ Deborah Bassett-Clarke ${ }^{1}$

To cite: Martini ND, van der Werf B, Bassett-Clarke D. Primary medication nonadherence at Counties Manukau Health Emergency Department (CMH-ED), New Zealand: an observational study. BMJ Open 2020;10:e035775. doi:10.1136/ bmjopen-2019-035775

- Prepublication history and additional material for this paper are available online. To view these files, please visit the journal online (http://dx.doi. org/10.1136/bmjopen-2019035775).

Received 15 November 2019 Revised 12 June 2020 Accepted 16 June 2020
Check for updates

(c) Author(s) (or their employer(s)) 2020. Re-use permitted under CC BY-NC. No commercial re-use. See rights and permissions. Published by BMJ.

${ }^{1}$ School of Pharmacy, The University of Auckland, Auckland, New Zealand ${ }^{2}$ Department of Epidemiology and Biostatistics, School of Population Health, The University of Auckland, Auckland, New Zealand

Correspondence to Dr Nataly Dominica Martini; n.martini@auckland.ac.nz

\section{ABSTRACT}

Objectives To measure primary medication nonadherence (failure to fill prescription medicines) in patients discharged from the emergency department (ED), and to determine whether sociodemographic factors, smoking status and access to a general practitioner affect prescription filling. Little is known about primary medication non-adherence in EDs, and less so in New Zealand (NZ). Identifying reasons for non-adherence will enable development of strategies to improve adherence and reduce morbimortality.

Design and setting An observational study based on patient data from the ED of a large public hospital in South Auckland, NZ.

Participants Data were collected from 1600 patients discharged between 28 April-6 May and 28 July-9 August 2014. Data were included if patients were residents within the Auckland Regional Public Health Service boundaries, admitted to ED and discharged with a prescription. Data were excluded if patients were admitted to another ward, transferred to another hospital or left the ED without seeing a doctor.

Results 992 patients were included in the study, the majority were under 10 years (32.6\%), of Pacific Island descent (42.8\%), NZ-born (67.7\%) and living in the most socioeconomically deprived areas (78.1\%). Almost 50\% of patients failed to fill all prescription medications. Simple linear regression analysis indicated that nonadherence was significant for those $10-24$ years $(n=236$; adherence $=47.2 \% ; p<0.05)$, of NZ Māori ethnicity $(n=175$; $51.3 \% ; p=0.01)$, unemployed $(n=77 ; 46.8 \% ; p<0.01)$, homemakers $(n=66 ; 45.7 \% ; p<0.01)$, students $(n=228$; $55.6 \% ; p<0.05)$ and cigarette smokers $(n=139 ; 50.3 \%$; $p<0.01$ ). Following multivariable analysis, the strongest predictors for non-adherence were those aged between 10 and 17 years $(n=116 ; p<0.01)$, the unemployed $(n=77$; $\mathrm{p}=0.01)$ and homemakers $(\mathrm{n}=66 ; \mathrm{p}=0.01)$.

Conclusions Age and occupation were the greater predictors of non-adherence; however, no other significant differences were found. Since this study, changes to prescription co-payments have been made. Further research is warranted to assess whether this change has more recently affected the rates of nonadherence.

\section{Strengths and limitations of this study}

- Data collected were ethnically representative of the patients who presented to Counties Manukau Health Emergency Department in 2014.

- Emergency department patient admission records were not always accurate or complete, and personal information was mainly obtained through patient self-reporting.

- Data were collected from a single centre, and the study was retrospective, which could have caused recall bias.

- Pharmacy dispensing software was only able to determine whether the pharmacy entered the prescription in their database (ie, dispensed), but not whether a patient picked up from the pharmacy or actually took the medicines, hence not indicative of adherence overall.

- Due to a small sample size ( $n=992)$ certain data were not able to be explored fully for statistical significance.

\section{INTRODUCTION}

Filling prescription medicines is an integral and critical first step in establishing patient adherence to a medicine regimen. ${ }^{1}$ Primary medication non-adherence, which is defined as the failure of a patient to fill a prescription when new medications are prescribed, ${ }^{23}$ results in poorer patient health outcomes and places a greater financial strain on the healthcare system. ${ }^{24}$

According to the 2016 US National Hospital Ambulatory Medical Care Survey, $80 \%$ of patients were discharged from an emergency department (ED) with a prescription. ${ }^{5}$ How many ED prescriptions are filled remains largely unknown as patient follow-up is often limited due to transient presentation, provision of incorrect contact details and patient self-reported levels of prescription filling/ adherence are often overstated. ${ }^{6}$ Studies which have investigated ED medication nonadherence suggest that around 12\%-22\% 
of adult prescriptions ${ }^{7-10}$ and $23 \%-66 \%$ of children's prescriptions will not be filled post-discharge. ${ }^{11}$

Predicting which factors are responsible for poor medication adherence is an essential step in guiding and developing adherence support interventions. Previous studies have shown that low socioeconomic status and/ or lower levels of income can influence a patient's approach to healthcare ${ }^{91213}$ and primary medicine nonadherence from the ED is known to be comparatively higher in patients with financial constraints. ${ }^{12-15}$ In New Zealand (NZ), the increase in prescription co-payment charge in 2013 from NZ\$3 to $\$ 5$ was shown to affect mostly people living in the lower socioeconomic, more deprived areas, where a large proportion of patients are unable to afford their prescription medicines. ${ }^{16}$ For these people, the co-payment increase resulted in patients delaying or avoiding filling their prescription, and/or selecting to fill only certain medicines. ${ }^{16}$ Patients may perceive certain medicines to be more essential than others, or they may lack awareness of the importance of the prescribed medicine, may already having a supply at home or are unwilling to pay for a medicine used short term. ${ }^{717}$

Age, gender, ethnicity and disease-related issues can also influence prescription filling behaviour, ${ }^{18-20}$ but correlation of these factors to medication adherence is often inconsistently reported in the literature. ${ }^{1115}$

In NZ, there is little known about primary medication non-adherence in the ED setting. The unique cultural mix and ethnic diversity in NZ warrants its own study, because variations in health beliefs inevitably lead to variable approaches in healthcare. ${ }^{21}$ Also, by being able to identify and measure the impact of demographic, socioeconomic and disease-related factors on primary medication non-adherence, this could allow for improved and targeted interventions to reduce both human and financial costs on the overall health budget of NZ. Different ethnic and cultural groups in NZ are known to have different approaches to health, which partially explains why some population subgroups may be more likely to use the ED as their first point of contact with a healthcare professional. ${ }^{21} 22$ NZ Māori and Pacific Peoples have previously been shown to display reduced adherence compared with other ethnic groups, and were more likely to postpone obtaining a prescription medicine. ${ }^{23}$ This is concerning given the higher healthcare needs of these indigenous groups and the greater barriers to accessing healthcare services compared with the majority population of NZ Europeans. ${ }^{21} 23$

The aim of this study was to measure primary medication non-adherence in patients discharged from Counties Manukau Health Emergency Department (CMH-ED) by recording whether patients collected their prescriptions post-ED discharge, and to determine if any relationships exist between non-adherence and factors such as the type and number of medicines prescribed, patient sociodemographics, smoking status and access to a regular general practitioner (GP).

\section{METHOD}

The study was conducted in accordance with the Strengthening the Reporting of Observational Studies in Epidemiology cross-sectional reporting guidelines. ${ }^{24}$

\section{Study design and setting}

The study was a retrospective, descriptive cohort study conducted in patients discharged from CMH-ED, Auckland, NZ.

CMH-ED is located in South Auckland-a diverse and economically deprived area of Auckland. The hospital has one of the busiest emergency departments in Australasia. In 2014, 106995 ethnically diverse people presented to CMH-ED; of these 33\% were Pacific Peoples, 32\% NZ European, 20\% NZ Māori and 13\% Asian. ${ }^{25}$

\section{Selection of participants}

Data were collected from the first 1000 patients that were discharged from CMH-ED between 28 April and 6 May (autumn), and a further 600 patients between 28 July and 9 August (winter), 2014. The gap between May and July was purposeful to enable comparison between seasons.

Patient data were eligible for inclusion if they were residents within the Auckland Regional Public Health Service boundaries, admitted to CMH-ED and discharged with a prescription for one or more medicines. Any patients presenting to ED who were subsequently admitted to another ward, transferred to another hospital, left CMH-ED without seeing a doctor or were discharged without a prescription, were excluded from the study.

\section{Data collection}

Undergraduate research assistants, who receive formal research training as part of their degree, identified eligible patients through CONCERTO (a programme that coordinates all patient data across the whole of the Auckland region in a central electronic platform) by limiting the search to 'ED specialty' and selecting the designated start date of the study. The patients were allocated a unique identifying code (UIC) to maintain confidentiality, which was linked back to their National Health Index (NHI) number for audit purposes. Patients who presented to the ED more than once during the study period were allocated the same UIC and only their first discharge was analysed.

A paper-based data collection tool was developed to facilitate documentation, and was piloted for efficiency using 50 patient records. Non-modifiable factors of the patient including age, gender, country of birth, residential suburb, ethnicity, language spoken and details of their regular primary physician (if available) were obtained from electronic hospital records in CONCERTO. Presenting indication, discharge date and time, smoking status, medicines provided on discharge and other comorbidities were obtained from available electronic and paper discharge summaries.

Information on whether patients filled their ED prescriptions from a community pharmacy was accessed 
via TestSafe found within the CONCERTO platform. TestSafe records all medicines (including generic and proprietary drug name, strength, quantity) prescribed to patients via their NHI, and information entered includes patient's name, address, gender and age; the prescriber's name; the date the item was supplied; how many medicines were dispensed at each dispensing and the contact details of the dispensing community pharmacy. For this study, Testsafe was used to provide data on whether all medicines on the prescription were entered into the system that is, dispensed by the pharmacy. Where pharmacists made generic substitutions to prescribed medicines, the item was still considered to be dispensed, and these were recorded accurately as generics on the database.

All New Zealanders are covered by a national public health system, which largely covers pharmaceuticals. For non-funded medications, the patient is required to pay full price for the medicine; however, those fully funded under the Preferred Medicines List (PML) attract a co-payment of $\$ 5$ per prescription item. At the time of this study, a $\$ 5$ co-payment applied to all PML medicines for all age groups except children under 6 years (who also received free doctor visits and any after-hours services); unemployed and other beneficiaries paid $\$ 2$ per prescription item. Once 20 items per nuclear family or individuals living alone has been reached, all prescription items are exempt from the co-payment fee for the remainder of the calendar year. About 30\%-35\% of New Zealanders have private health insurance and according to their chosen plan, prescription fees may be able to be reimbursed.

\section{Data validation}

Using the MS Excel randomisation function (=RANDBETWEEN), $20 \%$ of the total patient data set was randomly selected and manually cross-checked by two undergraduate researchers to ensure that the handwritten information on the paper tool matched the electronic patient record.

To ensure triangulation of the data, a randomised sample of 50 patients was selected by the same randomisation method. Approximately 1 year following presentation to the ED, a member of the research team telephoned the selected patients and using a pre-scripted telephone checklist, asked if they recalled whether they had picked up their medicine from a pharmacy following discharge. Patients were not asked to provide detail on which medications had been filled or not filled.

\section{Data entry and management}

Data were entered into an MS Excel spreadsheet and variables were coded for subsequent analysis. Ethnicity data were grouped into categories based on population data from Statistics New Zealand. The age structure was largely categorised according to Ministry of Health guidelines; however, those under 25 years were further divided into three categories as follows: under 10 years; $10-17$ years (school and teen working-aged) and 18-24 years (university students and younger working-aged population).
Suburb deprivation was coded using the 2013 NZ Indexes of Deprivation (NZDep2013). ${ }^{26}$ Occupation was categorised according to information available in the hospital notes. In many cases this was listed as 'other', and although these patients were adults between the ages of 18 and 65 , and of employable age, due to uncertainty around their employment status, it was decided to group them as a separate class; patients under the age of 5 years were classed as infants/children (data for the occupation of infant's parents/guardians were not available); students included children of school-going age (5-17 years) plus any others who were listed as a tertiary education student or likewise.

Patients were considered non-adherent if they did not fill all items on their prescription.

\section{Statistical analysis}

To evaluate adherence, Poisson regressions on the number of filled medicines were conducted with a generalised linear model with the log of the total prescribed medicines as the offset. This results in estimates for percentage filled. Simple linear regression analysis was compared with multivariable analysis. All possible one-way and twoway interaction terms of all available variables were evaluated to find the best fitting model. A stepwise procedure (repeated adding and dropping model terms) was used to find the multivariable model with the minimum value of the Akaike Information Criterion (AIC). The model with the minimum AIC value was considered the best fitting multivariable model. ${ }^{27}$ The evaluated independent (categorical) variables were age category, ethnicity, gender, country of birth, continent of birth, District Health Board (DHB), suburb deprivation, language, occupation, regular GP, smoking, discharge date, discharge day and discharge time. There were no missing data in the response variables (number of filled medicines and total number prescribed). An extra level 'unknown' was constructed for the missing values in the explanatory categorical variables. All analysis was conducted using the glm function of the core stats package of R (V.3.3.1, 64 bit). ${ }^{28}$ Priory pairwise comparisons were made to group the levels within the categorical variates using the covariance matrix derived from the fitted model. No parameter for each level within a group (denoted with a single letter) is significant from each other, alpha is 0.05 .

\section{Patient and public involvement}

This research was done without patient involvement in the design, outcomes or interpretation of the study. Patients were not invited to contribute to the writing, editing or dissemination of findings.

\section{RESULTS}

Data were collected from 1600 patients presenting to CMH-ED. Of these 608 patients were excluded. Reasons for exclusion are presented in table 1. 


\begin{tabular}{ll}
\hline Table 1 Reasons for patient data exclusion & \\
\hline Reason for exclusion & Number \\
\hline Discharged without a prescription from CMH-ED & 470 \\
Left the ED without seeing a doctor & 70 \\
Non-Auckland resident & 32 \\
Admitted to a ward at CMH & 19 \\
Transferred to another healthcare facility & 12 \\
Incomplete data & 5
\end{tabular}

CMH-ED, Counties Manukau Health Emergency Department.

The demographic data, smoking status and enrolment with a regular GP practice of eligible patients $(n=992)$ in the study are presented in table 2 . The patient cohort was predominantly between the ages of 0 and 24 years $(\mathrm{n}=559 ; 56.4 \%)$, NZ-born $(\mathrm{n}=660 ; 70.1 \%)$ and of Pacific Island descent $(\mathrm{n}=425 ; 42.8 \%)$. Gender representation was evenly proportioned with $50.1 \% \quad(\mathrm{n}=497)$ being women. Most patients were living in the Manukau region $(\mathrm{n}=797 ; 80.3 \%)$, and in the most socioeconomically deprived suburbs (NZdep9\&10) $(\mathrm{n}=775 ; 78.1 \%)$. A sizeable proportion of patients were listed as 'other' $(n=171$; $17.2 \%$ ) under 'occupation' in the clinical notes.

The majority of patients $(n=893 ; 90 \%)$ were prescribed between one and three medicines as seen in table 3 .

From the study population, $480(48.4 \%)$ patients did not fill at least one medication item on their prescription. Although men showed slightly higher adherence across all medicine classes compared with women, this was not significant. Age was a strong predictor of adherence with significantly poorer adherence seen in those aged $10-17$ years compared with those under 10 years $(43.4 \%$ vs $66.7 \%, p<0.01)$ and over 25 years $(p<0.01)$. Ethnicity data indicated significantly poorer adherence in NZ Māori compared with Middle Eastern, Latin American and African (51.3\% vs $83.3 \%, \mathrm{p}=0.046)$, NZ Europeans (51.3\% vs $64.1 \%, \mathrm{p}=0.014)$ and Pacific Peoples $(51.3 \%$ vs $60.3 \%, \mathrm{p}=0.014)$.

From the available data, patients who were born outside of NZ ( $\mathrm{n}=270 ; 27.2 \%$ ), of which 163 (60.3\%) were born in the Pacific Islands, showed significantly greater adherence compared with those born in NZ $(65.1 \%$ vs $57.6 \%, \mathrm{p}<0.05)$. And when comparing by continent of birth, patients born inside Oceania were found to be significantly less adherent than those born in Asia $(58.4 \%$ vs $71.7 \%, \mathrm{p}<0.05)$. The ability to speak English did not appear to affect adherence. Socioeconomic deprivation did not appear to have any effect on adherence rates, nor did the geographical area in which patients resided. Very few patients were reported as not having a regular GP, which did not appear to influence adherence rates overall. Current smokers showed significantly poorer adherence to non-smokers $(43.5 \%$ vs $58.6 \%$, $\mathrm{p}<0.01)$.

Homemakers and the unemployed were significantly less likely to be adherent compared with the infants/children $(45.7 \%$ and $46.8 \%$ vs $66.5 \%, \mathrm{p}<0.01)$ and retired patients $(66 \%, \mathrm{p}<0.05)$ whereas students were significantly less adherent than infants/children $(55.6 \%$ vs $66.5 \%, \mathrm{p}=0.03)$. A breakdown of the occupation status in each age category is shown in table 4 . It is important to note that for infants/children and students, the occupation status of their parents/guardians was not provided in the clinical files.

After fitting the age category and occupation into the multivariable statistical model, the strongest predictors of primary medication non-adherence were patients aged 10-17 years, and those who were classified as unemployed or homemakers (table 5 ).

\section{Discharge times and medicines}

Compared with the other days of the week, approximately double the number of patients presented to the ED on Monday ( $\mathrm{n}=238 ; 24 \%)$, and the most common discharge time was between $16: 00$ and 04:00 $(n=582 ; 58.7 \%)$ with a prescription. Bivariate analysis looking at discharge day and time did not yield any significant results or interactions (online supplementary table 1, online supplementary figure 1).

\section{Data validation}

From the 50 patients who were contacted, only 15 patients were able to be reached via telephone and agreed to talk to researchers (30\% response rate). Of these, two (13\%) reported that they did fill all items on their prescription, which conflicted with TestSafe dispensing records.

\section{DISCUSSION}

\section{Principle findings}

This study found that $48.4 \%$ of patients did not fill at least one medication prescribed following discharge from the ED. Simple linear regression analysis indicated that patients 10-24 years of age, of NZ Māori ethnicity, born in $\mathrm{NZ}$, were homemakers or unemployed and were cigarette smokers, exhibited poorer primary medication adherence compared with other groups in the study. When accounting for age and occupational status in multivariable analysis, the patients in the 10-17 year group were significantly less likely to fill their prescription $(p=0.002)$ as were those who listed as unemployed or homemakers $(\mathrm{p}=0.01)$.

\section{Comparison with existing literature}

Overall primary non-adherence in our study is higher than that of previously reported US studies, which cite non-adherence rates of $7 \%-35 \% \cdot{ }^{29}$ As there is a paucity of research available on primary medication non-adherence in NZ EDs, we were unable to compare this result with other hospitals across NZ where it is likely that there are fewer patients with complex health needs and/or differing health beliefs.

At the time of this study, CMDHB-ED experienced the second highest rate of ED admissions from all hospitals in NZ, with over 100000 events reported. ${ }^{30}$ According to 
Table 2 Patient characteristics and simple linear regression analysis $(n=992)$

Percentage filled

\begin{tabular}{|c|c|c|c|c|c|c|c|c|c|}
\hline Variable & n (\%) & RR & Lower 95\% & Upper 95\% & P value & $\%$ & Lower 95\% & Upper 95\% & Group \\
\hline \multicolumn{10}{|l|}{ Gender } \\
\hline Male & 495 (49.9) & 1.00 & & & & 61.8 & 57.3 & 66.6 & $\mathrm{a}$ \\
\hline \multicolumn{10}{|l|}{ Age } \\
\hline$>64$ & $59(5.9)$ & 1.00 & & & & 69.4 & 55.5 & 86.8 & a \\
\hline $45-64$ & $159(16)$ & 0.95 & 0.74 & 1.23 & 0.7018 & 66 & 58.7 & 74.3 & a \\
\hline $25-44$ & $215(21.7)$ & 0.84 & 0.66 & 1.08 & 0.1746 & 58.4 & 52.3 & 65.2 & $a b$ \\
\hline $18-24$ & $120(12.1)$ & 0.74 & 0.56 & 0.97 & 0.0282 & 51 & 43.5 & 59.8 & $b c$ \\
\hline $10-17$ & $116(11.7)$ & 0.63 & 0.47 & 0.84 & 0.0018 & 43.4 & 35.8 & 52.5 & c \\
\hline \multicolumn{10}{|l|}{ Ethnicity } \\
\hline Pacific peoples & 425 (42.8) & 0.72 & 0.5 & 1.05 & 0.0849 & 60.3 & 55.5 & 65.6 & a \\
\hline Unknown & $5(0.5)$ & 0.74 & 0.34 & 1.61 & 0.4461 & 61.5 & 30.7 & 123.2 & $a b$ \\
\hline Asian & $157(15.8)$ & 0.73 & 0.5 & 1.07 & 0.1097 & 61 & 53.4 & 69.7 & $a b$ \\
\hline Māori & 175 (17.6) & 0.62 & 0.42 & 0.9 & 0.013 & 51.3 & 44.9 & 58.8 & $\mathrm{bc}$ \\
\hline \multicolumn{10}{|l|}{ Country of birth } \\
\hline Outside NZ & $270(27.2)$ & 1.00 & & & & 65.1 & 59.2 & 71.6 & a \\
\hline Unknown & $50(5)$ & 0.9 & 0.7 & 1.15 & 0.3917 & 58.3 & 46.1 & 73.8 & $a b$ \\
\hline $\mathrm{NZ}$ & $672(67.7)$ & 0.88 & 0.89 & 0.99 & 0.0406 & 57.6 & 53.8 & 61.8 & $\mathrm{~b}$ \\
\hline \multicolumn{10}{|l|}{ Continent of birth } \\
\hline \multicolumn{10}{|l|}{ Language } \\
\hline Non-English & $61(6.2)$ & 1.00 & & & & 64.1 & 51.1 & 80.4 & a \\
\hline English & 877 (88.4) & 0.93 & 0.74 & 1.18 & 0.5564 & 59.8 & 56.4 & 63.3 & a \\
\hline Unknown & $54(5.4)$ & 0.91 & 0.65 & 1.28 & 0.5935 & 58.5 & 45.6 & 75 & a \\
\hline \multicolumn{10}{|c|}{ Suburb deprivation* } \\
\hline 5 & $18(1.8)$ & 1.00 & & & & 77.5 & 54.5 & 110.2 & a \\
\hline 3 & $16(1.6)$ & 0.89 & 0.51 & 1.53 & 0.6674 & 68.7 & 45.2 & 104.5 & a \\
\hline 6 & $43(4.3)$ & 0.87 & 0.57 & 1.33 & 0.5161 & 67.3 & 53.1 & 85.4 & $\mathrm{a}$ \\
\hline 7 & $35(3.5)$ & 0.87 & 0.55 & 1.35 & 0.5271 & 67.1 & 51 & 88.3 & a \\
\hline 4 & $44(4.4)$ & 0.86 & 0.57 & 0.32 & 0.5003 & 67 & 52.9 & 84.8 & $\mathrm{a}$ \\
\hline 1 & $9(0.9)$ & 0.86 & 0.46 & 1.62 & 0.6401 & 66.7 & 39.5 & 112.6 & a \\
\hline 10 & 405 (40.8) & 0.78 & 0.54 & 1.12 & 0.1758 & 60.4 & 55.5 & 65.7 & a \\
\hline 8 & $25(2.5)$ & 0.76 & 0.46 & 1.25 & 0.2816 & 58.8 & 41.1 & 84.2 & a \\
\hline 9 & 370 (37.3) & 0.73 & 0.51 & 1.05 & 0.0906 & 56.6 & 51.7 & 62 & a \\
\hline 2 & $23(2.3)$ & 0.6 & 0.35 & 1.04 & 0.0705 & 46.8 & 30.8 & 71.1 & a \\
\hline Unknown & $4(0.4)$ & 0.59 & 0.23 & 1.51 & 0.2682 & 45.5 & 18.9 & 109.3 & a \\
\hline
\end{tabular}

Continued 
Table 2 Continued

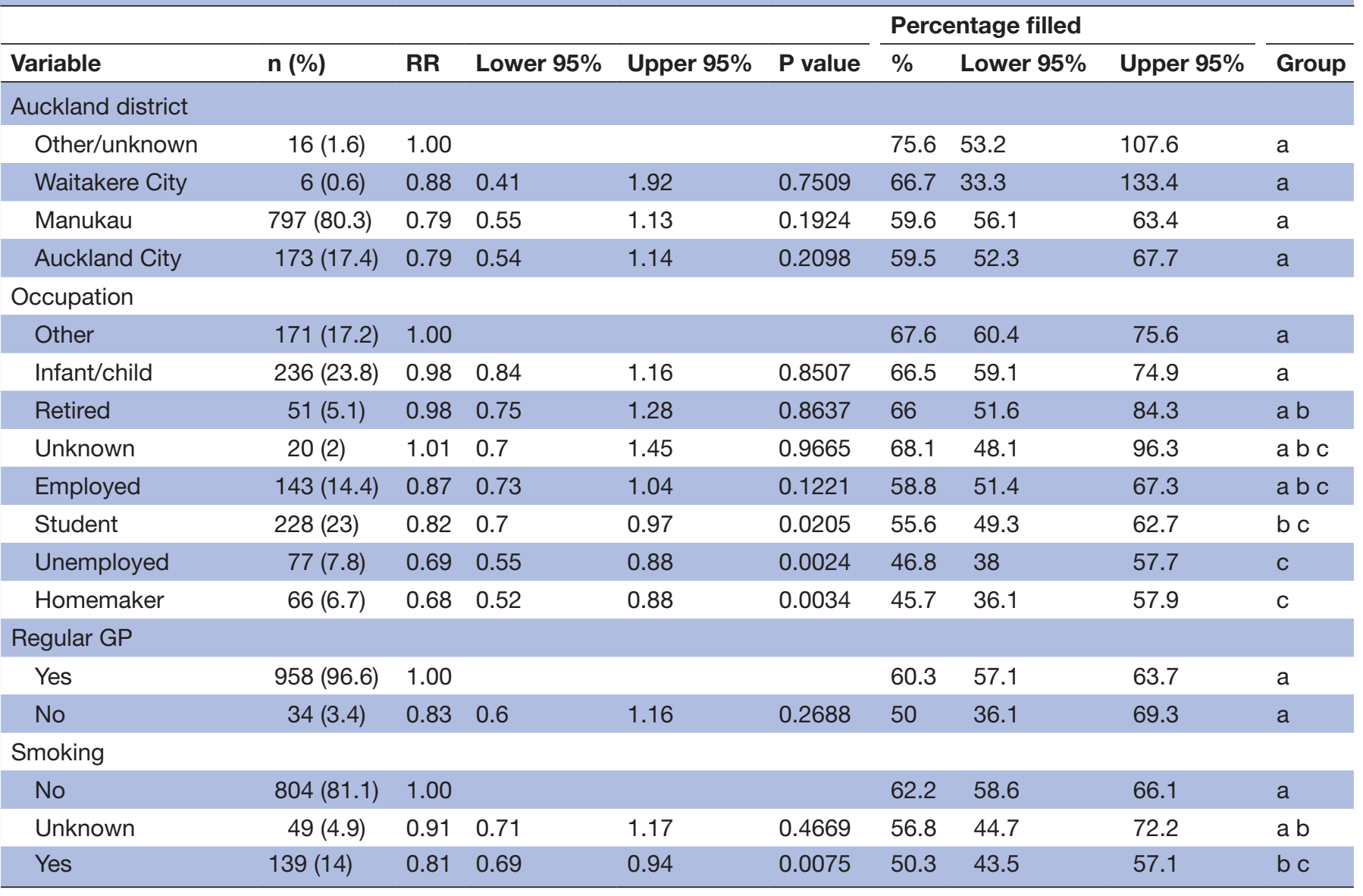

*Suburb deprivation: 1 represents areas of least deprived; 10 is most deprived.

GP, general practitioner; MELAA, Middle Eastern, Latin American and African; NZ, New Zealand; RR, rate ratio.

this report, men consistently exhibited higher rates of ED use to women. ${ }^{30}$ While the female sex is reported to be a predictor of low adherence, findings are often inconsistently reported in the literature. ${ }^{29} 3132$ In our study, men and women presented in similar numbers, and women were shown to be more non-adherent than men; however, this was not significant.

Children under the age of 15 years form the largest proportion of ED presenters, with children under 5 years exhibiting the greatest rates of ED utilisation. ${ }^{30}$ The largest group of patients in our study were under 10 years of age, and the most significant predictor of non-adherence were children/teenagers in the 10-17 year-old age group. Literature is conflicting, with some reports suggesting no difference in adherence between various paediatric age groups, ${ }^{33}$ while other studies show that prescriptions not filled following paediatric discharge are more common

Table 3 Number of medications prescribed for patients

\section{Number of medicines prescribed}

$$
\begin{array}{llllllllll}
1 & 2 & 3 & 4 & 5 & 6 & 7 & 8 & 12 & 14
\end{array}
$$

$\begin{array}{lllllllllll}\text { Number of } & 290 & 362 & 241 & 71 & 17 & 7 & 1 & 1 & 1 & 1\end{array}$
patients among older children, boys and lower income families or those without public health insurance. ${ }^{34} 35$ At the time of this study, the co-payment charge for prescription items was NZ $\$ 5$ per item (a $\$ 2$ increase from 2013), and this was applied to all patients over the age of 6 years, regardless of income status. ${ }^{16}$ This may account for the finding that infants and children under the age of 5 in our study had higher adherence rates than older children. In the older age group of 18-24 years, simple linear regression analysis showed significantly poorer adherence when compared with children under 10 years and those over 45 years. This has been seen elsewhere. ${ }^{31}$ This association disappeared, however, when controlling for occupation in multivariable analysis. This could partially be explained by the heterogeneity in occupation of this age group, with almost $50 \%$ of the patients categorised as student, unemployed or homemaker. Alone, these factors did not predict non-adherence but when controlling for age, those who were unemployed or classed as homemakers were found to be significantly less likely to fill their prescriptions. This is most likely attributed, at least in part, to prescription costs. Younger patients are also thought to have lower adherence due to less established or continuous relationships with a primary care provider, ${ }^{31}$ and in an ED setting, 
Table 4 Occupation status of patients classified according to their age category

\begin{tabular}{lrllrrrrrr}
\hline Age & Student $^{*}$ & Unemployed & Homemaker & Retired & Other & Employed & Infant/child $\dagger$ & Unknown & Total \\
\hline$<10$ & 87 & & & & & & 236 & & 323 \\
$(10,17)$ & 109 & 3 & & & 2 & & & 2 & 116 \\
$(18,24)$ & 25 & 19 & 13 & & 33 & 25 & & 5 & 120 \\
$(25,44)$ & 4 & 25 & 34 & 1 & 77 & 64 & & 10 & 215 \\
$(45,64)$ & 3 & 28 & 19 & 2 & 52 & 52 & & 3 & 159 \\
$>64$ & 2 & & & 48 & 7 & 2 & & & 59 \\
Total & 228 & 77 & 66 & 51 & 171 & 143 & 236 & 20 & 992 \\
\hline
\end{tabular}

*Students were patients of school-going age (5-17 years) and others listed as 'student' in their file. †Infants and children were patients under the age of 5 years.

healthcare providers are usually unfamiliar with their patient's lifestyle and/or resources. ${ }^{10}$

Medication cost is commonly cited as a significant barrier to medication adherence ${ }^{29}$ and predominantly affects those living in poverty. The rate of ED use increases with the level of neighbourhood deprivation; in 2014/2015, one in five people who presented at ED resided in the most deprived neighbourhoods. ${ }^{30}$ During this same period, Pacific peoples exhibited the highest rate of ED use across NZ (19.3 per 100 population), followed by Māori (18 per 100 population). ${ }^{30}$ Evidence suggests that NZ Māori and Pacific peoples are more likely to be affected by cost due to typically being lower income earners, and hence less likely to fill their prescriptions. ${ }^{16}$ In our study, although NZ Māori exhibited significantly poorer adherence compared with all other ethnicities except Asian patients in the simple linear regression analysis, this disappeared after fitting age class and occupation. This indicates that in our patient cohort, age and occupation are better descriptors of non-adherence, and that there is probably a skewed age and occupation distribution among different ethnicities in our study. Other NZ studies have suggested that NZ Māori and Pacific Peoples are 2.9 and 3.5 times less likely than a NZ European to fill a prescription medicine, respectively. ${ }^{23}$ Lower socioeconomic status, residence in areas of higher deprivation and differing approaches to health, have been suggested as possible reasons for differing adherence rates. ${ }^{21} 23$ Similar trends can be seen in the US, where African American and Hispanics have lower prescription filling rates following ED discharge compared with their European American counterparts, most often due to poorer socioeconomic and financial reasons. ${ }^{6}$ Each unfilled prescription may result in a missed treatment opportunity and when extrapolated to larger populations can exacerbate pre-existing health disparities. ${ }^{35}$ Furthermore, the link between smoking and non-adherence found in our study aligns with previous work suggesting that smoking

Table 5 Multivariable analysis

\begin{tabular}{|c|c|c|c|c|c|c|c|c|}
\hline \multirow{2}{*}{ Variable } & \multirow[b]{2}{*}{ Levels } & \multirow[b]{2}{*}{$\mathbf{R R}$} & \multirow[b]{2}{*}{ Lower 95\% } & \multirow[b]{2}{*}{ Upper 95\% } & \multirow[b]{2}{*}{$P$ value } & \multicolumn{3}{|c|}{ Estimated percentage filled } \\
\hline & & & & & & $\%$ & Lower 95\% & Upper $95 \%$ \\
\hline \multirow[t]{6}{*}{ Age in years } & $<10$ & 1.00 & & & & 54.9 & 41.8 & 72.2 \\
\hline & $(10,17)$ & 0.65 & 0.50 & 0.85 & 0.002 & 36.0 & 27.1 & 47.7 \\
\hline & $(18,24)$ & 0.91 & 0.66 & 1.25 & 0.546 & 49.8 & 41.7 & 59.4 \\
\hline & $(25,44)$ & 1.07 & 0.76 & 1.52 & 0.681 & 59.0 & 51.0 & 68.4 \\
\hline & $(45,64)$ & 1.22 & 0.86 & 1.74 & 0.262 & 67.1 & 57.3 & 78.7 \\
\hline & $>64$ & 1.43 & 0.81 & 2.52 & 0.218 & 78.5 & 51.7 & 119.4 \\
\hline \multirow[t]{8}{*}{ Occupation } & Student & 1.00 & & & & 68.3 & 56.0 & 83.3 \\
\hline & Unemployed & 0.66 & 0.47 & 0.92 & 0.014 & 44.9 & 35.3 & 57.0 \\
\hline & Homemaker & 0.62 & 0.44 & 0.89 & 0.010 & 47.4 & 32.6 & 55.9 \\
\hline & Retired & 0.69 & 0.39 & 1.24 & 0.215 & 42.7 & 30.1 & 74.7 \\
\hline & Other & 0.92 & 0.68 & 1.23 & 0.555 & 62.5 & 53.1 & 73.7 \\
\hline & Employed & 0.79 & 0.58 & 1.07 & 0.131 & 54.0 & 44.8 & 65.1 \\
\hline & Infant/child & 0.99 & 0.80 & 1.24 & 0.940 & 67.7 & 51.3 & 89.3 \\
\hline & Unknown & 0.99 & 0.64 & 1.52 & 0.959 & 67.5 & 46.8 & 97.5 \\
\hline
\end{tabular}

$\mathrm{RR}$, rate ratio. 
is a barrier to adherence, ${ }^{11}{ }^{36}$ and is influenced by demographic and socioeconomic factors such as a lower level of education and income. ${ }^{11}$

ED visits often occur at unplanned times and/or when pharmacy services are not available, which affects the ability for patients to fill their prescriptions immediately. ${ }^{36}$ In NZ, one in three ED events occur at the weekend, between Friday 17:00 and Monday 08:00. ${ }^{30}$ With no 24 hours pharmacies in Auckland, and only three afterhours pharmacies where patients could fill their prescriptions located within the CMDHB boundaries (none of which are open after 21:00), we anticipated higher primary medication non-adherence after-hours or on Sundays when most pharmacies are closed. This was not seen in our study where discharge time and day did not appear to affect the level of prescription filling. Nevertheless, access to a pharmacy remains a significant barrier to filling a prescription for many patients, ${ }^{35} 36$ and the costs of travel may compete with other demands, leading to non-adherence with possible worsening of the condition and/or readmission. Where an onsite pharmacy has been available at an ED, adherence rates were shown to be substantially higher, ${ }^{29}$ justifiably arguing the need for the provision of late-night pharmacies in areas where accessibility and cost are barriers for patients.

\section{Strengths and limitations}

Student researchers collected data at several time points in this study, thus providing a good representation over several months in the ED. The data collected were validated by two researchers by randomly selecting $20 \%$ of the total sample and was found to have $5 \%$ error rate.

As this study was retrospective, patient's details and prescription filling behaviour were collected with fewer potential sources of bias. The exclusion criteria of this study ruled out any patients with chronic disease(s) in order to focus on the study setting that is, focused in simple medical issues requiring immediate treatment. This study was conducted at a single ED site at $\mathrm{CMH}$ which would allow specific future interventions to enhance medicine adherence to be more easily tested and implemented.

Limitations of this study included a small sample size, selection bias, given the study population was obtained from consecutive patients during only 1 month of the year and recall bias as patients were telephoned a year after collecting their prescription items. Also, because medication adherence was inferred in this study if a prescription was filled, true adherence rates were likely to be lower than reported as not every medicine collected from the pharmacy is always taken by the patient. The TestSafe system only displays the prescriptions that have been entered into the dispensary system, but not whether the prescription has been collected, or taken by the patient. Furthermore, 2 of 15 patients reported conflicting dispensing records with TestSafe, giving a suggested error rate of $13 \%$. These differences, however, could be based on inaccurate recall or biased by social desirability. Moreover, ED patient admission records were not always accurate or complete, as they are often written under time constraints and personal information was mainly obtained through patient self-reporting. The study did not have a systematic way to differentiate certain ethnicities either. For example, Fijian Indians may have identified themselves as Fijian, Indian, Asian and/or Fijian Indian, and adherence rates for this ethnic group may therefore vary considerably from the larger Polynesian group.

\section{Unanswered questions and future research}

Studies on predictors of ED non-adherence often report contradictory findings. This is owing to the multiple factors that influence non-adherence, such as patient sociodemographic and psychological influences, ED system factors, pharmacy accessibility and access to medical insurance or financial support. Many of these factors were not able to be assessed in our study due to our retrospective method. Moreover, pharmacy data used to determine whether patients had filled prescriptions. This meant that we were unable to determine whether patients failed to fill a prescription due to an existing home supply of medicine, had experienced symptom resolution and no longer required medication such as analgesics, or were given a 'back-pocket prescription' (delayed prescribing) that was no longer required. A prospective longitudinal study of a larger sample size would allow for these questions to be answered at the time, and not have to rely solely on patient recall. Additionally, possible adverse effects over time, and readmission rates due to non-adherence could have been able to provide further insights.

Given the small cohort and patient demographics at CMH-ED, it is not possible to generalise the results to other EDs across NZ where there may be patients with different health needs and/or health beliefs. Since the time of this study, there have been considerable changes to the ethnic distribution of patients at CMH-ED, as well as changes to the prescription co-payment structure. Although the $\$ 5$ co-payment has remained the same in NZ, free paediatric prescriptions have been extended to age 13 years. Additionally, several discount pharmacies have been offering free prescriptions for all patients. While it is suspected that this will ease the financial burden for people who are unable to afford prescription co-payments, the effect of these changes to adherence rates is yet to be determined. Further research is required to identify those patients in the community most likely to need targeted interventions to improve adherence to prescribed medications from ED departments across NZ.

Twitter Nataly Dominica Martini @MartiniNataly

Acknowledgements Thank you to Tarik Al-Diery, Shannon Carey, Shannon Chow, Salja Kumar, Joanna Liang, Aaron Naidoo and Hamish Wu for assistance with data collection, and Professor Gregory Luke Larkin for guidance. We also gratefully acknowledge the support offered by the School of Pharmacy, The University of Auckland, for travel and printing costs.

Contributors NDM and DB-C contributed equally to the conception and design of the work. NDM: substantial contribution to the analysis and interpretation of the data, and writing the paper for submission. DB-C: substantial contribution to the 
acquisition of the data for the study. BvdW: substantial contribution to the analysis and interpretation of the data.

Funding The authors have not declared a specific grant for this research from any funding agency in the public, commercial or not-for-profit sectors.

Competing interests None declared.

Patient consent for publication Not required.

Ethics approval Ethics approval was granted by the University of Auckland Human Participants Ethics Committee (Reference No. 012463) and a locality agreement was approved by the Counties Manukau District Health Board Research Committee.

Provenance and peer review Not commissioned; externally peer reviewed.

Data availability statement Data are available upon reasonable request. Data are deidentified patient data and are available from the corresponding author upon reasonable request. n.martini@auckland.ac.nz ORCID identifier 0000-0002-99008883.

Open access This is an open access article distributed in accordance with the Creative Commons Attribution Non Commercial (CC BY-NC 4.0) license, which permits others to distribute, remix, adapt, build upon this work non-commercially, and license their derivative works on different terms, provided the original work is properly cited, appropriate credit is given, any changes made indicated, and the use is non-commercial. See: http://creativecommons.org/licenses/by-nc/4.0/.

\section{ORCID iDs}

Nataly Dominica Martini http://orcid.org/0000-0002-9900-8883

Bert van der Werf http://orcid.org/0000-0003-3072-5937

\section{REFERENCES}

1 Matsui D, Joubert GI, Dykxhoorn S, et al. Compliance with prescription filling in the pediatric emergency department. Arch Pediatr Adolesc Med 2000;154:195-8.

2 Fischer MA, Stedman MR, Lii J, et al. Primary medication nonadherence: analysis of 195,930 electronic prescriptions. J Gen Intern Med 2010;25:284-90.

3 Adams AJ, Stolpe SF. Defining and measuring primary medication nonadherence: development of a quality measure. J Manag Care Spec Pharm 2016;22:516-23.

4 Blanchard J, Madden JM, Ross-Degnan D, et al. The relationship between emergency department use and cost-related medication nonadherence among Medicare beneficiaries. Ann Emerg Med 2013;62:475-85.

5 National Hospital Ambulatory Medical Care Survey. 2016 emergency department summary tables. 38, 2016.

6 Ding R, Zeger SL, Steinwachs DM, et al. The validity of self-reported primary adherence among Medicaid patients discharged from the emergency department with a prescription medication. Ann Emerg Med 2013;62:225-34.

7 Hohl CM, Abu-Laban RB, Brubacher JR, et al. Adherence to emergency department discharge prescriptions. CJEM 2009;11:131-8.

8 Ginde AA, Von Harz BC, Turnbow D, et al. The effect of ED prescription dispensing on patient compliance. Am J Emerg Med 2003;21:313-5.

9 Saunders CE. Patient compliance in filling prescriptions after discharge from the emergency department. Am J Emerg Med 1987;5:283-6.

10 McCarthy ML, Ding R, Roderer NK, et al. Does providing prescription information or services improve medication adherence among patients discharged from the emergency department? A randomized controlled trial. Ann Emerg Med 2013;62:212-23.

11 Davis DP, Jandrisevits MD, lles S, et al. Demographic, socioeconomic, and psychological factors related to medication nonadherence among emergency department patients. J Emerg Med 2012;43:773-85.

12 Thomas EJ, Burstin HR, O'Neil AC, et al. Patient noncompliance with medical advice after the emergency department visit. Ann Emerg Med 1996;27:49-55.
13 Reed M, Brand R, Newhouse JP, et al. Coping with prescription drug cost sharing: knowledge, adherence, and financial burden. Health Serv Res 2008;43:785-97.

14 Klein D, Turvey C, Wallace R. Elders who delay medication because of cost: health insurance, demographic, health, and financial correlates. Gerontologist 2004;44:779-87.

15 Heaton PC, Tundia NL, Luder HR. U.S. emergency departments visits resulting from poor medication adherence: 2005-07. J Am Pharm Assoc 2013;53:513-9.

16 Norris P, Tordoff J, Mclntosh B, et al. Impact of prescription charges on people living in poverty: a qualitative study. Res Social Adm Pharm 2016;12:893-902.

17 Jones I, Britten N. Why do some patients not cash their prescriptions? Br J Gen Pract 1998;48:903-5.

18 Fischer MA, Choudhry NK, Brill G, et al. Trouble getting started: predictors of primary medication nonadherence. Am J Med 2011;124:1081.e9-1081.e22.

19 Bazargan M, Barbre AR, Hamm V. Failure to have prescriptions filled among black elderly. J Aging Health 1993;5:264-82.

20 Kennedy J, Erb C. Prescription noncompliance due to cost among adults with disabilities in the United States. Am J Public Health 2002;92:1120-4.

21 Bassett-Clarke D, Krass I, Bajorek B. Ethnic differences of medicines-taking in older adults: a cross cultural study in New Zealand. Int J Pharm Pract 2012;20:90-8.

22 Gellad WF, Haas JS, Safran DG. Race/ethnicity and nonadherence to prescription medications among seniors: results of a national study. $J$ Gen Intern Med 2007;22:1572-8.

23 Jatrana S, Crampton P, Norris P. Ethnic differences in access to prescription medication because of cost in New Zealand. J Epidemiol Community Health 2011;65:454-60.

24 von Elm E, Altman DG, Egger M, et al. The strengthening the reporting of observational studies in epidemiology (STROBE) statement: guidelines for reporting observational studies. J Clin Epidemiol 2008;61:344-9.

25 Rea H, Kenealy T, Horwood F, et al. Integrated systems to improve care for very high intensity users of hospital emergency department and for long-term conditions in the community. N Z Med J 2010;123.

26 Ministry of Health NZ. NZ DEP 2013 index of deprivation. Available: https://www.health.govt.nz/publication/nzdep2013-index-deprivation [Accessed 25 Oct 2019].

27 Springer New York. Formal Inference From More Than One Model: Multimodel Inference (MMI). In: Burnham KP, Anderson DR, eds. Model selection and Multimodel inference: a practical information-theoretic approach. New York, NY: Springer New York, 2002: 149-205.

28 Bates D, Mächler M, Bolker B, et al. Fitting Linear Mixed-Effects Models Using Ime4. J Stat Softw 2015;67:1-48.

29 Farris B, Shakowski C, Mueller SW, et al. Patient nonadherence to filling discharge medication prescriptions from the emergency department: barriers and clinical implications. Am J Health Syst Pharm 2018;75:316-20.

30 Ministry of health NZ. Emergency department use 2014/15 [Internet]. Available: https://www.health.govt.nz/publication/emergencydepartment-use-2014-15 [Accessed 11 Nov 2019].

31 Feehan M, Morrison MA, Tak C, et al. Factors predicting selfreported medication low adherence in a large sample of adults in the US general population: a cross-sectional study. BMJ Open 2017;7:e014435.

32 Ho J, Taylor DM, Cabalag MS, et al. Factors that impact on emergency department patient compliance with antibiotic regimens. Emerg Med J 2010;27:815-20.

33 Sammons NW, Yin H. Compliance of medications prescribed from a pediatric emergency department. Pediatr Emerg Care 2015;31:399-402.

34 Rosman SL, Dorfman D, Suglia SF, et al. Predictors of prescription filling after visits to the pediatric emergency department. Pediatr Emerg Care 2012;28:22-5.

35 Hensley C, Heaton PC, Kahn RS, et al. Poverty, transportation access, and medication nonadherence. Pediatrics 2018;141:e20173402.

36 Yamamoto LG, Manzi S, et al, Committee on pediatric emergency medicine. Dispensing medications at the hospital upon discharge from an emergency department. Pediatrics 2012;129 